\title{
Design and Fabrication of Flexible Management Robot Vehicle (AGV)
}

\author{
B. Samuvel Michael, R .Praveen, MD Namsheed Jashal, Unais M S, Amil Raju
}

\begin{abstract}
This project is focusing on developing a multifunctional automated guided vehicle. This AGV system has to be obtained by the major part of all workstations into shop floor. This type of vehicle is assigned to all over the shop floor. This article has presented as an analytical concept of design a AGV system. The concept model has obtained a performing of design procedure which consists of two steps, 'selection of feasible zones' and 'selection of final guide path.'This AGV for all manufacturing industry which contains the features like it can carry the finished component pallets, collision detection and computer control. A command based or teach pendent interface based wireless control is provided to control the robot. A collision detection sensor ensures robot may not hit any obstacles in its path. The robot has compact size which can easily move on rough area. In this project we describe the development of automated guided vehicle that provides you with a FMS environment for modeling and prototyping automated guided vehicles
\end{abstract}

Keyword: prototype agv, system, remote

\section{INTRODUCTION}

The present work is to design a $\mathrm{AGV}$ which has a design of following line path and avoid the obstacles. This AGV has to be designed the able to followed a yellow line on the ground without getting off the line too much and avoid the obstacle in front of the AGV on the yellow colour path[1]. An AGV is a programmable vehicle it is used in industries to move material in shop floor It has the capability to move materials at low expenses. By using frequency selected mode, vision based mode etc. the path is selected so that AGV is automated. This vehicle has to handle the material must be safely, efficiently, at low cost in timely manners and accurately without damage to the material. The material handling cost must be lower than the convention material handling cost compared to total production cost[2]. The estimating average around $10-15 \%$ of total manufacturing cost[3].

Revised Manuscript Received on December 30, 2019.

* Correspondence Author

B.Samuvel Michael, Research Scholar, Department of Mechanical Engineering,

Aarupadai Veedu Institute of Technology, Vinayaka Mission Research Foundation, sammic69@gmail.com.com

R. Praveen, Department Of Mechanical Engineering, Aarupadai Veedu Institute Of Technology, Vinayaka Mission Research Foundation, Sammic69@Gmail.Com.Com

MD Namsheed Jashal, UG Students Aarupadai Veedu Institute of Technology, Vinayaka Mission'S Research

Unais M S, UG Students Aarupadai Veedu Institute of Technology, Vinayaka Mission'S Research

Amil Raju, UG Students Aarupadai Veedu Institute of Technology, Vinayaka Mission'S Research

(C) The Authors. Published by Blue Eyes Intelligence Engineering and Sciences Publication (BEIESP). This is an open access article under the CC BY-NC-ND license (http://creativecommons.org/licenses/by-nc-nd/4.0/)

\section{PROPOSED METHOD}

The block diagram of proposed vehicle is shown in Fig 1. The working of AGV is pretty straightforward. This AGV can be detected a yellow or dark line are-on the surface depending on the indication., Based on this respective signals will be control the motors, and may be turn tp left or right of a to movement are maintain to steady centre with respect to the time. These robots has be send the light ray of light emitting sensors, in order to measure distance of the reflectance light and rays of the surface beneath them as in Fig 2. The basic criteria is that yellow line has absorb by rays are lesser reflectance values. These absorbed values are lesser when AGV can move forward. This low value has to send the low reflectance is the parameter used to detect the position of the line by the robot. If the higher value has to reflect can be the surface around the line its stop the vehicle.

The light emitting ray sensor consists of individual LEDs and decoders. The LEDs and decoders have to be able to control the AGV by micro controller. The photodiode has to be gives an output voltage proportional to the reflectance of the surface

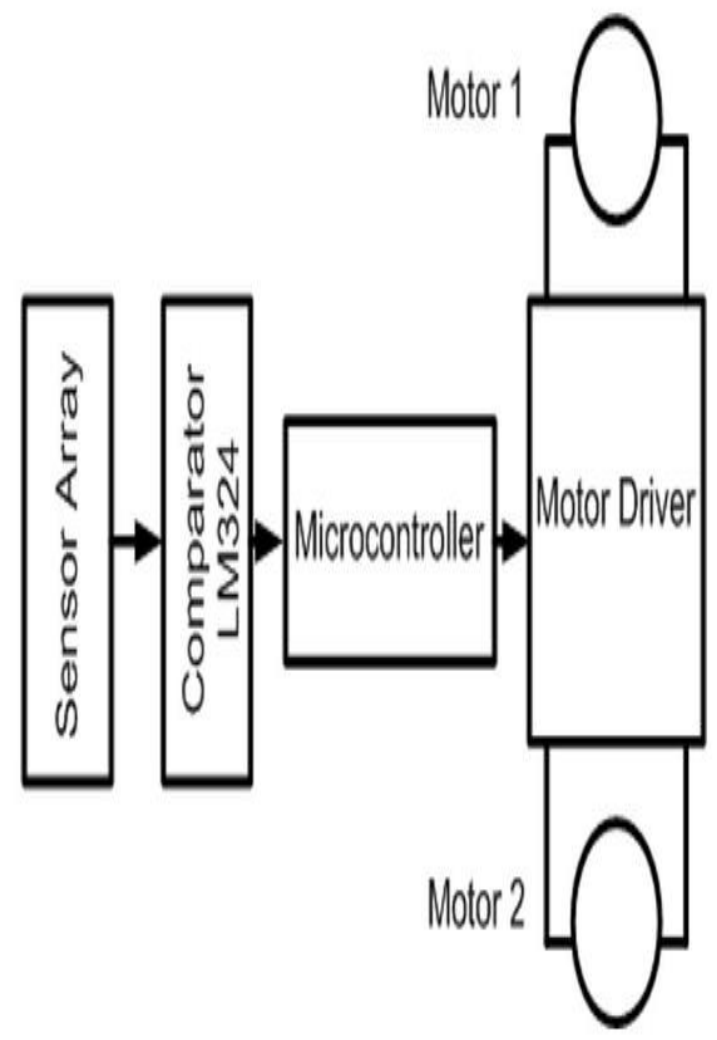

Fig. 1.Block Diagram of Robot 


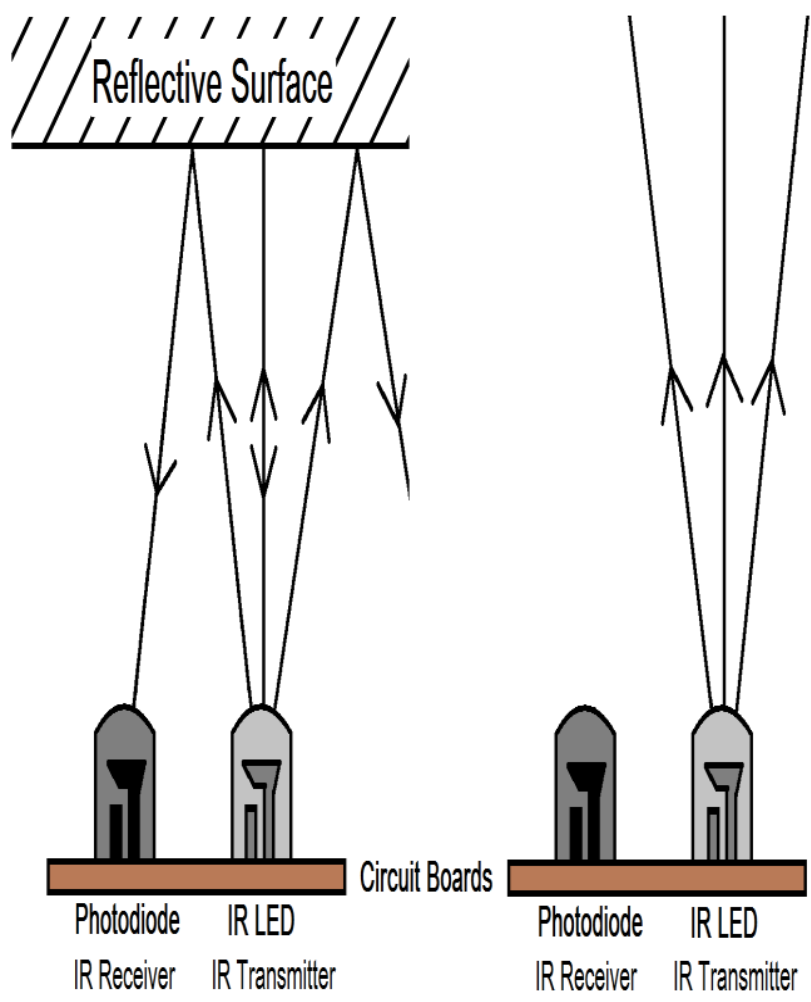

Fig. 2. Sensor setup

\section{RESULT AND DISCUSSION}

The robot is built with ATMEGA328 PU, L293D, IR sensors, LM324, platform consisting on the platform. This AGV has two motors and it is fixed with vehicle wheel. The light emitting sensors are fixed at the bottom of the platform for detect path tracking tape. By this arrangement it can captures the line path with the help of this optical sensors. In front of the vehicle LED sensor are fixed to guide vehicle. When this sensor detect black surface and send the signal to microcontroller. It will send the output to comparator (LM324). When it is low logic and for dark path the output and it is high logic for yellow path. If it is deduct the yellow path the vehicle can move forward. When it is deduct the dark path it will stop the vehicle. This microcontroller has to be control the movement of the vehicle.

The basic operation of the line follower is to track the line with any steering mechanism. To achieve this we use two motors governing wheels motion.

\section{ARDUINO PROGRAM USED}

\author{
Arduino Pin || IR PIN \\ 2 || IR_LEFT \\ 3 || IR_RIGHT \\ Ârduino Pin || MOTOR PIN \\ 8 || MOTOR_L_F \\ 9 || MOTOR_L_B \\ 10 || MOTOR_R_B \\ 11 || MOTOR_R_F \\ $* * * * * * * * * * * * * * * * * * * * * 1$
}

\#define START_KEY 'A'

\#define STOP_KEY 'S'

\#define IR LEFT A0 \#define IR_RIGHT A1

\#define IR_OBSTACLE A2

\#define MOTOR_L_F 4

\#define MOTOR_L_B 5

\#define MOTOR_R_B 06

\#define MOTOR_R_F 07

547

l]

1

\#

define DIRECTION(a,b,c,d)

\{digitalWrite(MOTOR_L_F,a);

digitalWrite(MOTOR_L_B,b);

digitalWrite(MOTOR_R_B,c);

digitalWrite(MOTOR_R_F,d); \}

\#define FORWARD ( DIRECTION $(0,1,1,0)$

\section{CONCLUSION}

These type of vehicle has widely used in most of the industries. This vehicle can reduce the workload of man power, time,cost. Mainly this type of equipment is used for load shifting purpose. The centralized computer control system can control the flow of materials in shop floor. This system has to be coupled with automated stores. AGVs can be very effectively used for placing order directly from production area for bringing parts and storing them back automatically.

\section{REFERENCES}

1. McKinsey Corporation, Cologne, Germany Department of Industrial ngineeringand Engineering Management, Stanford University, Stanford, CA 94305-40245

2. k. k. lai AGV problem via a Self-Organizing Neural Journal of the Automated Guided Vehicle wednesday, April 23,2008.

3. Kyunghoon Jung1, Jungmin Kim2, Sungshin Kim2Department Localization AGV Using Extended Kalman Filter of Interdisciplinary cooperative Course: Robot 2 School of Electrical and computer Engineering 1,2Pusan National University Geumjeong, Busan 609-735, Korea me.vol1.issue1.15

\section{AUTHORS PROFILE}

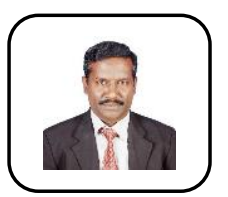

B.Samuvel Michael, Research Scholar, Department of Mechanical Engineering, Aarupadai Veedu Institute of Technology, Vinayaka Mission Research Foundation, sammic69@gmail.com.com

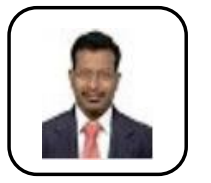

R. Praveen, Department Of Mechanical ngineering, Aarupadai Veedu Institute Of Technology, Vinayaka Mission Research Foundation, Sammic69@Gmail.Com.Com 
Namsheed Jashal MD, UG Student Department of Mechanical Engineering, Aarupadai Veedu Institute of Technology, Vinayaka Mission

Research Foundation, sammic69@gmail.com.com

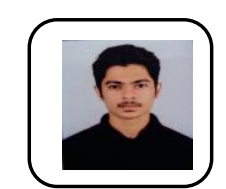

Unais MS, UG stusentDepartment of Mechanical Engineering, Aarupadai Veedu Institute of Technology, Vinayaka Mission Research Foundation, sammic69@gmail.com.com

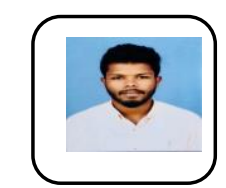

Amil Raju, UG Student Department of Mechanical Engineering, Aarupadai Veedu Institute of Technology, Vinayaka Mission Research Foundation, sammic69@gmail.com.com 